\title{
Shuji Nakamura Named 1997 MRS Medalist
}

A scientist from a small Japanese chemical company who has stunned the materials community with his accomplishments on blue and green light-emitting diodes (LEDs) has been selected to receive the 1997 MRS Medal Award. This honor recognizes recent distinguished and innovative achievements or discoveries which are expected to have a major impact on the progress of any materials-related field. Shuji Nakamura (Nichia Chemical Industries) has been recognized for "the development of lattice-mismatched $\mathrm{GaN}$ based heteroepitaxy and its application to the creation of blue and green light-emitting diodes and short wavelength laser diodes."

Nakamura has single-handedly transformed a materials system (GaN, AIN, InN) that as recently as 1989 was a scientific backwater into a continuous series of compelling research accomplishments. He not only developed commercially available, high-brightness blue and green LEDs, but also produced the first electrically pumped, continuous-wave blue laser diodes. He established the growth of the very difficult InGaN alloys as active layers in the devices, despite their vastly different growth temperatures relative to the AlGaN cladding layers, GaN contact layers, and phase separation, to produce quantum dots that dominate the emission process and the influence of growth reactor atmosphere, geometry, and V/III ratio on material quality.

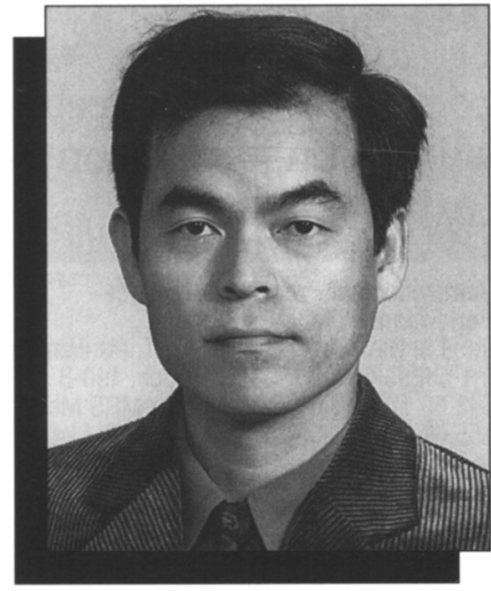

Shuji Nakamura

Nakamura started his research on group III-nitrides in 1989, and succeeded in developing a blue LED with a luminous intensity as high as $2 \mathrm{~cd}$ in 1993. In 1995, he developed high brightness, single-quantum-well-structure blue LEDs with luminous intensities about 100 times greater than those of conventional blue SiC LEDs and green GaP LEDs. In 1995, he also developed a bluish-violet laser diode using III-nitride materials.

Nakamura's influence has ranged from crystal growth and basic materials science to full-scale commercialization. Nitride lasers appear destined to become the tech- nology of choice for information storage and related fields requiring short wavelengths and high energy density. The LEDs and lasers have enormous potential for such areas as optical data storage, full-color displays, traffic lights of vastly improved brightness and reliability, white light sources (currently made at Nichia using blue LEDs to excite white light from phosphors), solar blind ultraviolet detectors, and covert communications. This work has also opened the possibility for high performance power electronics by demonstrating the superb transport characteristics of the nitride materials. Applications for $\mathrm{GaN}$ power electronics include switching on power grids, automotive (especially the allelectric vehicle), military avionics, and industrial motor drives.

Nakamura received $\mathrm{BE}, \mathrm{MS}$, and $\mathrm{PhD}$ degrees in electrical engineering from the University of Tokushima, and joined Nichia Chemical Industries in 1979. In 1988, he was a visiting research associate at the University of Florida. He has published 58 papers and holds numerous patents in Japan, Europe, Korea, Taiwan, and the United States.

Nakamura will give his award talk "IIINitride Lasers and Optoelectronic Devices" for Symposium X of the 1997 MRS Fall Meeting in Boston, Massachusetts, on Thursday, December 4, at 12:05 p.m. in Salon E, Marriott Hotel.

\section{Plenary Speaker Harry Y. McSween Jr. to Address Materials Findings of the Mars Pathfinder}

According to Harry Y. McSween Jr., professor and former head of the Department of Geological Sciences at the University of Tennessee, the Mars Pathfinder mission "provided the first chemical analyses of martian rocks, as well as new analyses of soils." McSween, currently a member of science teams for both the Mars Pathfinder and Mars Global Surveyor spacecraft missions, will address these studies in his plenary talk at the Fall 1997 Materials Research Society Meeting in Boston on December 1, at 6:00 p.m. in Salon $\mathrm{E}$ of the Boston Marriott.

The rock and soil samples from Mars were tested with the Alpha-Proton-XraySpectrometer (APXS), through which three kinds of interactions with matter occur: alpha backscattering, production of protons from alpha-proton reactions, and excitation of $x$-rays. Rocks were found to contain higher contents of $\mathrm{Si}, \mathrm{Al}$, and alkalis than martian meteorites previously studied. Chemicals in soil were found

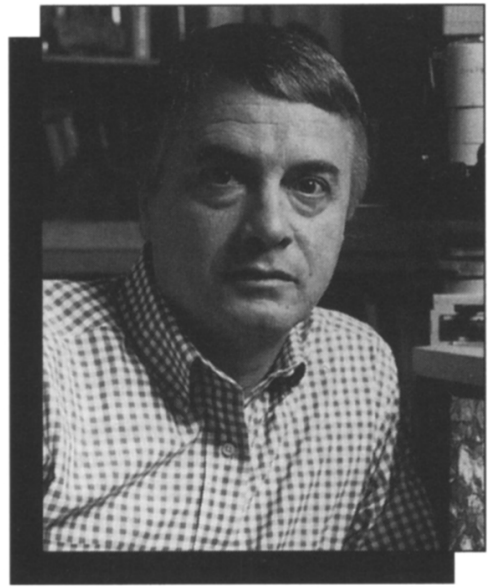

Harry Y. McSween Jr.

to be similar to those occurring during the formation of terrestrial palagonite, which, McSween said, suggest "a role for water in determining soil chemistry."
McSween's research interests focus on mineralogic and chemical studies of meteorites, particularly those from Mars. $\mathrm{He}$ has been an often-quoted voice of caution in interpreting reported evidence for early Martian life in one of those meteorites.

With degrees from The Citadel (BS in chemistry), the University of Georgia (MS in geology), and Harvard University (PhD in geology), McSween has recently served as president of the Meteoritical Society, chair of the Planetary division of the Geological Society of America, national lecturer for the Mineralogical Society of America, and as a member of numerous advisory panels for the National Aeronautics and Space Administration (NASA) and the National Academy of Sciences. He is author of over 100 papers, a geochemistry textbook, and popular science books including Stardust to Planets: A Geological Tour of the Solar System and Fanfare for Earth: The Origin of Our Planet and Life. MRIS 